\title{
A comparison of flight of colours with visually evoked responses in patients with multiple sclerosis
}

\author{
SONIA SWART AND PAUL MILLAC \\ From the Department of Neurology, Leicester Royal Infirmary
}

SUMMARY The flight of colours test was performed in a series of patients with multiple sclerosis. Visually evoked responses were then measured in the same patients. The two tests were found to be comparable in their ability to detect disturbance in the visual system.

The flight of colours is the series of after images which results when a bright light is directed at the retina and then withdrawn. ${ }^{1}$ These take the form of circles and haloes of light which fade, change and reappear in sequence over a period of a few minutes. This phenomenon forms the basis for a simple test which detects abnormalities of central vision. ${ }^{2}$ In a recent study it was found to be abnormal in $74 \%$ of patients with multiple sclerosis (MS). ${ }^{3}$

Measurement of visually evoked responses (VERs) is now a well established means of detecting subclinical lesions in the visual pathway. ${ }^{4}$ Its value lies in the high incidence of abnormality detected in MS patients with no visual symptoms or signs. We set out to compare the two methods in a group of patients with MS.

\section{Method}

The flight of colour test (FOC) was performed on 20 patients with MS (18 definite, one probable and one possible according to MacAlpine's criteria) and one patient with optic neuritis. ${ }^{5}$ There were 14 women and seven men whose ages ranged from 26 to 53 years. Their symptoms had been present between a few months and 20 years. Ten of them gave a history suggesting optic neuritis whilst six complained of diplopia or blurred vision; the remaining five had no visual symptoms. The tester was not aware of which eyes had a history of optic neuritis.

Address for reprint requests: Dr P Millac, Consultant Neurologist The Leicester Royal Infirmary, Leicester LE1 5WW.

Accepted 1 April 1980
The test was carried out as described by Feldman et al. ${ }^{2}$ Dark adaptation was achieved by asking the patient to wear a pair of ultraviolet goggles for a period of five minutes. With both eyes closed one flap of the goggles was raised and the eye that was exposed was opened. Immediately a bright pocket torch was directed at that eye from an inch away for 10 seconds. The goggles were then replaced and the patient, with closed eyes, reported all after images. Each eye was tested separately with an interval of at least 15 minutes between tests.

This method was first applied to 10 patients with nonneurological disease. Each patient was tested on two occasions. All the patients saw images for $2 \frac{1}{2}$ minutes or longer on both occasions. They also saw at least four different colours and at least four changes of image during the first minute, but for any individual patient the figures varied between the two testings.

Measurement of FOC were made without knowledge of the VERs which were estimated in the neurophysiology department using midline scalp electrodes and a reversing black and white checkerboard. The normal range of latencies at $2 \mathrm{~Hz}$ using our apparatus, as standardised on a normal population, was 110-125 ms.

\section{Results}

In the 36 eyes examined the correlation between VERs and the duration of image in the FOC is shown in the figure. If a latency of less than $125 \mathrm{~ms}$ is taken as normal and a persistence of after images for more than $2 \frac{1}{2}$ minutes, then the results of the 
two tests corresponded in 33 out of 36 observations $(92 \%)$.

Amongst the 10 patients with a history of optic neuritis 15 out of 18 eyes were abnormal for both FOC and VER. Two eyes gave normal results for both tests and in one instance the VER was prolonged with a normal FOC. Three patients in the group had an abnormal result for both tests on one side and a normal response for both in the other eye.

Of nine eyes tested in those patients complaining of diplopia or blurred vision, six had both FOC and VERs that were abnormal. Two were normal in both respects and in one case the FOC was abnormal with a normal VER.

When the patient had no visual symptoms, abnormalities both of FOC and VER were still detected in four out of the nine eyes tested. In one instance the FOC was abnormal whilst the latency was normal. The remaining four were normal by both methods.

\section{Discussion}

VERs may assist in the diagnosis of MS by revealing subclinical lesions of the visual pathway and thereby an additional site of involvement within the nervous system. They add a degree of objectivity and may therefore be of particular value when there are psychological problems. However, VERs require special staff and equipment which means they are not universally available and are relatively costly.

We have shown that the FOC compares favourably with the VER in its ability to detect abnormality in the visual system. With careful explanation patients had little difficulty in understanding and executing the test. The use of ultraviolet goggles for dark adaptation improved compliance and made the test usable in an ordinary room. The FOC cannot claim to be as objective a measurement as the VER but it does have the advantage that it can be performed readily at the bedside or in the clinic without any sophisticated equipment. We suggest the FOC is a most useful and cost-effective investigation.

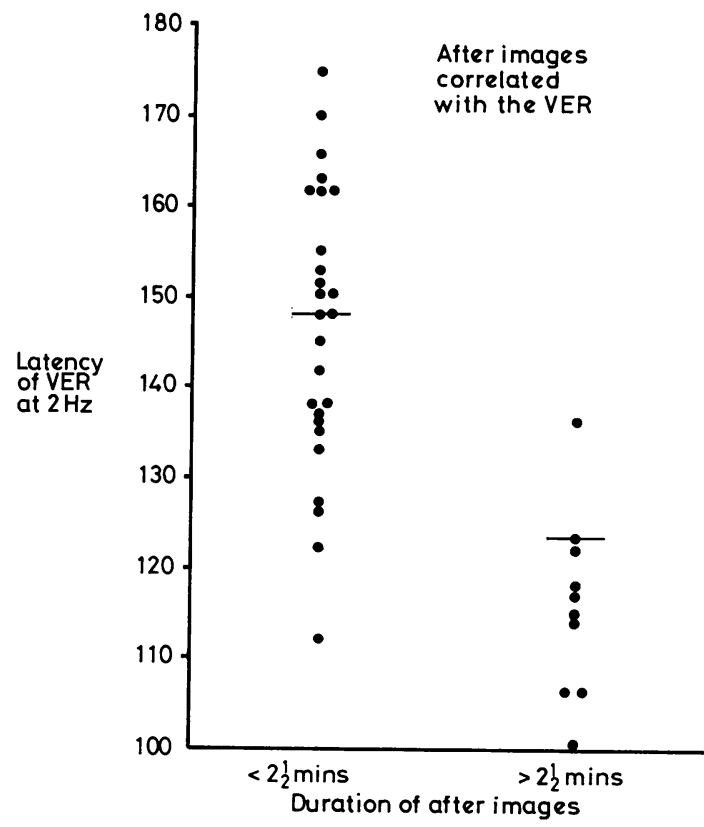

Figure The latency of the VER in ms. is plotted against the duration of image in the FOC. The median value of the VER is shown to fall within the normal range when the duration of after images is $2 \frac{1}{2}$ minutes or more and well outside this range when the duration of images is less than $2 \frac{1}{2}$ minutes.

\section{References}

1 Berry W. The flight of colours in the after image of a bright light. Psych Bull, 1932; 19:307-37.

2 Feldman L, Todman L, Bender B. "Flight of colours" in lesions of the visual system. $J$ Neurol Neurosurg Psychiatry, 1974; 37:1265-2.

3 Mourik J, van Donselaar CA, Minderhoud JM. Disturbed "Flight of Colours" in Multiple Sclerosis. Lancet, 1978; 108.

4 Halliday AM, McDonald WI, Mushin, J. Visual Evoked Response in Diagnosis of Multiple Sclerosis. Br Med J, 1973; 4:661-4.

5 MacAlpine D, Lumsden CE, Acheson ED. Multiple Sclerosis: a Reappraisal. Edinburgh: Churchill Livingstone, 1972; 202. 